\title{
Modification of Ground Tire Rubber-Promising Approach for Development of Green Composites
}

\author{
Lukasz Zedler ${ }^{1, *(\mathbb{D})}$, Marta Przybysz-Romatowska ${ }^{1}\left(\mathbb{D}\right.$, Józef Haponiuk ${ }^{1}\left(\mathbb{D}\right.$, Shifeng Wang ${ }^{2}$ and \\ Krzysztof Formela 1 ,*(D)
}

1 Department of Polymer Technology, Faculty of Chemistry, Gdańsk University of Technology, Gabriela Narutowicza 11/12, 80-233 Gdańsk, Poland; marta.przybysz@pg.edu.pl (M.P.-R.); jozef.haponiuk@pg.edu.pl (J.H.)

2 Department of Polymer Science and Engineering, Shanghai Jiao Tong University, Shanghai 200240, China; shfwang@sjtu.edu.cn

* Correspondence: lukzedle@student.pg.edu.pl (Ł.Z.); krzysztof.formela@pg.edu.pl (K.F.)

Received: 29 October 2019; Accepted: 16 December 2019; Published: 20 December 2019

\begin{abstract}
Ground tire rubber (GTR) was mechano-chemically modified using a road bitumen 100/150 and two types of organic peroxides: di-(2-tert-butyl-peroxyisopropyl)-benzene (BIB) and dicumyl peroxide (DCP). The impact of used additives on reactive sintering efficiency and physico-mechanical properties of modified GTR was investigated using oscillating disc rheometer measurements, followed by tensile tests and swelling behavior studies. It was found that the application of bitumen and both used peroxides (DCP/BIB) improves processing and reactive sintering efficiency better than untreated GTR. However, the results indicate that BIB is more prone to blooming on the surface of modified GTR, thus limiting (especially at higher content) its application as a modifier and promotor of GTR reactive sintering.
\end{abstract}

Keywords: waste tires; recycling; modification; reactive sintering

\section{Introduction}

The management and environmentally friendly recycling of waste rubbers has been a huge challenge for industry and scientists since the vulcanization process was invented [1-7]. One of the most problematic waste rubber to the environment is used tires, which constitute $\sim 80 \%$ of total waste rubbers generated each year. Tires are high-quality products which must meet all safety requirements in order to be put into service. However, the outstanding properties of tires become problematic after the end of their service life. The reason behind this is the chemical and physical structure of vulcanized rubber, which does not decompose easily [8]. The cross-linked structure and the presence of unreacted curatives, additives and plasticizers make the waste rubber a serious threat to the environment, leading to the pollution of local surface and groundwater and fires [9], and their design is perfect for breeding sites for mosquitoes spreading diseases [10].

Without meaningful and industrially applied recycling methods, end-of-life tires (ELTs) are still commonly disposed of in landfills, which has been illegal in Europe since 2003 [11].

Among many existing recycling technologies of ELTs, energy recovery is still the most used method, which utilizes waste tires as an alternative fuel in cement kilns and power plants [12]. Even though this approach is extremely non-environmentally friendly, it is still acceptable to industries and governments due to the lack of a better solution to the rising problem. Under those circumstances, many attempts have been made to find an appropriate recycling method of ELTs.

Over the years, scientists have focused their efforts on reclaiming and modifying ground tire rubber (GTR) in order to obtain new products with unique properties or to apply the GTR as a filler 
or modifier in different polymer composites $[13,14]$. One of the industrially applicable solutions is the reactive sintering of GTR by applying high pressure and temperature [15]. The process can be done without additives and with the use of curing systems or adhesive binders. However, it should be noted that this method is limited to the production of low-cost products with simple shapes and low-quality requirements. In order to improve reactive sintering efficiency and further application of GTR, an interesting and promising approach seems to be modification or functionalization of GTR.

GTR reclaiming usually requires a high temperature, high shear forces and other specific conditions necessary for the essence of the process, which is the scission of cross-linking bonds. The control of the process parameters is essential to find a balance between selective scission of cross-linking bonds and the unwanted degradation of main polymeric chains, which affect the final properties of the obtained reclaimed rubber $[16,17]$. On the other hand, there are solutions to improve reclaiming efficiency, such as the application of reclaiming agents facilitating the process [18,19]. It must be pointed out that some of the commonly used agents are used as curing additives [20,21]. Following this logic, it is possible to apply peroxides as a source of free radicals. Those would allow the formation of new bonds between polymer chains, while perhaps simultaneously degrading the main polymeric chains.

Despite the application of a reclaiming agent, the processing of GTR may be still difficult. One of the solutions to enhance GTR processability during reclaiming is the application of low-cost plasticizers, such as heavy oils from pyrolysis of tires [22], disulfide oil [23] or bitumens [24]. The obtained results indicate that the plasticization of GTR allows the selective scission of cross-linked bonds, which has a beneficial influence on the mechano-chemical reclaiming efficiency as well as enhancing the processing of GTR.

However, to the best of our knowledge, there are no published data about the combined impact of plasticizer and curing additive on the efficiency of reactive sintering of GTR. In this work, GTR was mechano-chemically modified in the presence of bitumen and two types of organic peroxides. The effect of the applied treatment procedure on the reactive sintering of treated GTR was evaluated by curing characteristics and physico-mechanical properties.

\section{Materials and Methods}

\subsection{Materials}

GTR was kindly provided by Grupa Recykl S.A. (Śrem, Poland). The material was obtained by grinding used tires in ambient atmosphere (mix of passenger car tires and truck tires). The particle size distribution of the used GTR was determined by the sieve analysis. Seven sieves with different mesh sizes were chosen: $1.5 \mathrm{~mm}, 1.0 \mathrm{~mm}, 0.8 \mathrm{~mm}, 0.5 \mathrm{~mm}, 0.355 \mathrm{~mm}$ and $0.212 \mathrm{~mm}$. The initial mass of the tested GTR was $100 \mathrm{~g}$. The obtained results are presented in Figure 1. Road bitumen 100/150 with penetration at $25^{\circ} \mathrm{C}: 100-150(1 / 10 \mathrm{~mm})$ and softening point: $39-47^{\circ} \mathrm{C}$ was received from Lotos Asfalt Sp. z o.o. (Gdańsk, Poland). BIB and DCP were obtained from the Pergan Peroxides Company (Bocholt, Germany). The chemical structures and selected properties of used peroxides are presented in Figures 2 and 3 and Table 1.

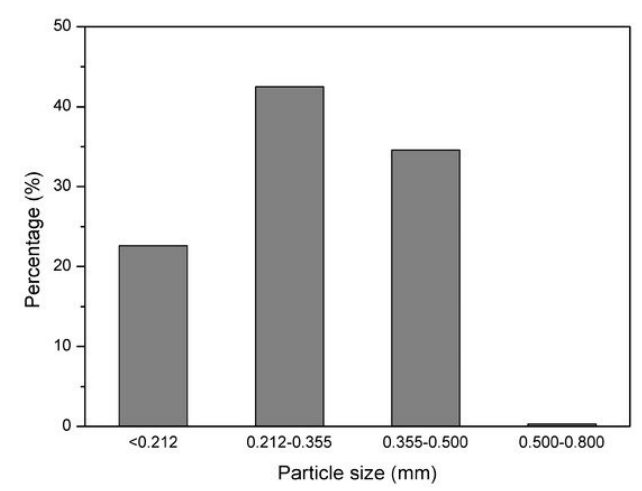

Figure 1. Particle size distribution of ground tire rubber (GTR). 
<smiles>CC(C)(C)OOC(C)(C)c1ccc(C(C)(C)OOC(C)(C)C)cc1</smiles>

Figure 2. Chemical structure of di-(2-tert-butyl-peroxyisopropyl)-benzene (BIB).

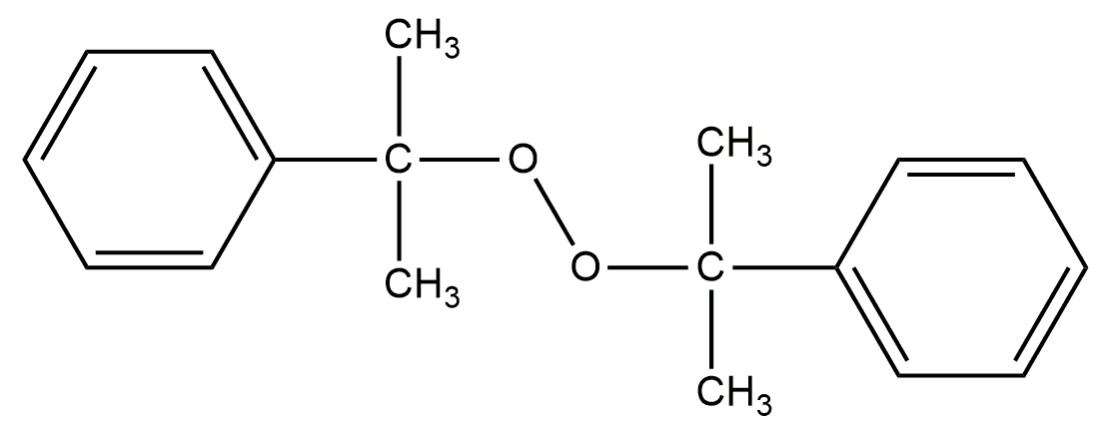

Figure 3. Chemical structure of dicumyl peroxide (DCP).

Table 1. Characteristics of used organic peroxides.

\begin{tabular}{cccc}
\hline Name & Abbreviation & $\begin{array}{c}\text { Active Oxygen } \\
(\%)\end{array}$ & $\begin{array}{c}\text { The Half-Life } \\
\text { Temperature }\left({ }^{\circ} \mathbf{C}\right) *\end{array}$ \\
\hline $\begin{array}{c}\text { Di-(2-tert-butyl-peroxyisopropyl)-benzene } \\
\text { Dicumyl peroxide }\end{array}$ & BIB & 8.98 & 169 \\
\hline
\end{tabular}

* Datasheet from Pergan GmbH.

\subsection{Sample Preparation}

The compositions of the prepared samples is presented in Table 2. The samples were mechano-chemically modified at ambient temperature, within $10 \mathrm{~min}$, using two-roll mills model 14201/P2 from Buzuluk (Komárov, Czech Republic). During the process, GTR was modified with $10 \mathrm{phr}$ of bitumen as a reactive plasticizer as well as two types of organic peroxides, which are a source of free radicals allowing the formation of new bonds between polymer chains, while simultaneously possibly causing main chain degradation. The obtained samples were compression-molded into 2-mm thick samples at $180{ }^{\circ} \mathrm{C}$ and $4.9 \mathrm{MPa}$ according to the determined optimal cure time or (if not determined) for $5 \mathrm{~min}$. For a better understanding of the obtained data, the reference sample of the unmodified GTR was prepared in the same conditions as the other samples.

Table 2. The compositions and codings of the studied samples.

\begin{tabular}{|c|c|c|c|c|c|c|}
\hline \multirow{2}{*}{$\begin{array}{c}\text { Components } \\
\text { (phr) }\end{array}$} & \multicolumn{6}{|c|}{ Sample Code } \\
\hline & GTR & GTR/B ${ }^{a}$ & GTR/B BIB0.5 $^{b}$ & GTR/B BIB2.0 $^{b}$ & GTR/B ${ }_{\text {DCP0.5 }}{ }^{c}$ & GTR/B ${ }_{\text {DCP2.0 }}{ }^{c}$ \\
\hline GTR & 100 & 100 & 100 & 100 & 100 & 100 \\
\hline Bitumen 100/150 & - & 10 & 10 & 10 & 10 & 10 \\
\hline BIB & - & - & 0.5 & 2.0 & - & - \\
\hline DCP & - & - & - & - & 0.5 & 2.0 \\
\hline
\end{tabular}




\subsection{Measurements}

The vulcanization process of the prepared samples was investigated using a Monsanto R100S rheometer with an oscillating rotor (USA) in accordance with ISO 3417. In order to determinate the cross-linking rate, the cure rate index (CRI) was calculated according to the Formula (1):

$$
C R I=\frac{100}{t_{90}-t_{1}}
$$

where $t_{90}$-optimum vulcanization time (equal to $90 \%$ of maximal torque), min; $t_{1}$-scorch time (time equal to $1 \mathrm{dNm}$ rise above minimal torque), min.

Determination of $R_{300}$ parameter allowed to investigate the aging resistance of prepared samples at raised up temperature. $R_{300}$ is calculated from the time at which torque reaches the maximum value $\left(M_{H}\right)$ and it describes the percentage of reversion degree after period of $300 \mathrm{~s}$ [25]. It was calculated according to Formula (2):

$$
R_{300}=\frac{M_{H}-M_{300 \mathrm{~s}}}{M_{H}} \times 100 \%
$$

where $M_{H}$-maximum torque, $\mathrm{dNm} ; M_{300 \mathrm{~s}}$-torque $300 \mathrm{~s}$ after maximum torque, $\mathrm{dNm}$.

The tensile strength, elongation at break and modulus at $100 \%$ of elongation $\left(\mathrm{M}_{100}\right)$ were estimated in accordance with ISO 37. Tensile tests were carried out on the Zwick Z020 machine (Germany) at a constant speed of $500 \mathrm{~mm} / \mathrm{min}$. Direct extension measurements were conducted periodically using an extensometer with sensor arms. The reported results stem from at least five measurements for each sample. Shore hardness type A was assessed using a Zwick 3130 durometer (Germany) according to ISO 7619-1.

The density of the samples was measured based on the Archimedes method, as described in ISO 1183. Accordingly, all measurements were carried out at room temperature in methanol medium.

The swelling degree of sintered GTR samples $(0.2 \mathrm{~g})$ was estimated via a swelling test carried out in toluene at room temperature. The swelling degree was calculated according to Equation (3):

$$
Q=\frac{m_{t}-m_{0}}{m_{0}} \times 100 \%
$$

where $Q$ —swelling degree, $\% ; m_{t}$-mass of the sample swollen after time $\mathrm{t}, \mathrm{g}$; $m_{0}$ —initial mass of sample, g.

Sol fraction was determined as the mass difference of sintered GTR before swelling $\left(W_{1}\right)$ and after extraction $\left(W_{2}\right)$, according to Equation (4):

$$
\text { Sol fraction }=\frac{W_{1}-W_{2}}{W_{1}} \times 100 \%
$$

\section{Result and Discussion}

\subsection{Curing Characteristics}

The effect of the road bitumen 100/150 and two types of peroxides (DCP/BIB) on curing characteristics of modified GTR samples is presented in Figure 4 and summarized in Table 3. According to the presented data, the reference sample and GTR modified with bitumen 100/150 do not show typical curing curves for the vulcanization process. This is due to the lack of any additional curing systems inside the composition, however, the addition of road bitumen shifts the curve to the lower torque values. This indicates that applied bitumen significantly influences processing properties, which is a critical aspect of GTR recycling and the quality of the product [26]. The lack of a typical curing curve is noticeable for GTR/B $\mathrm{B}_{\mathrm{DCP} 0.5}$, even though, for the same amount of $\mathrm{BIB}$ in GR/B $\mathrm{B}_{\mathrm{BIB} 0.5}$, the vulcanization process occurs. This is due to the structure of applied peroxides (Figures 2 and 3 ). BIB possesses the higher capability to creates free radicals (higher active oxygen content) causing 
the formulation of additional covalent bonds during reactive sintering, and the process itself can be detected even at a low concentration of the peroxide.

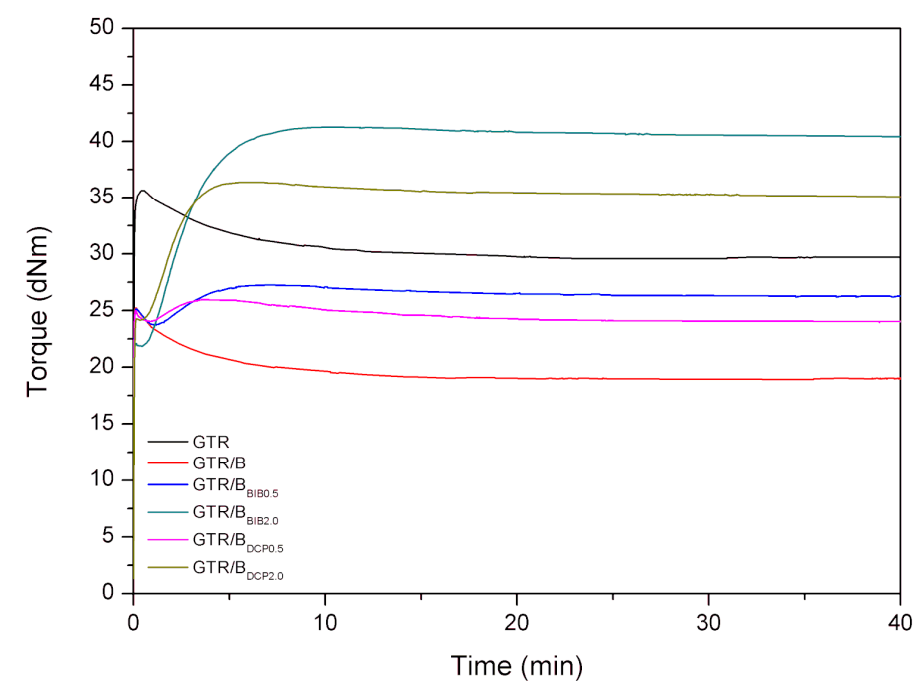

Figure 4. Curing curves of the studied samples (curing at $180^{\circ} \mathrm{C}$ ).

Table 3. Curing characteristics of modified GTR performed at $180^{\circ} \mathrm{C}$.

\begin{tabular}{ccccccc}
\hline \multirow{2}{*}{ Properties } & \multicolumn{5}{c}{ Sample Code } \\
\cline { 2 - 7 } & GTR & GTR/B & GTR/B BIB0.5 & GTR/B BIB2.0 $_{\text {GTR/B }}$ & GCP0.5 & GTR/B $_{\text {DCP2.0 }}$ \\
\hline Minimal torque $(\mathrm{dNm})$ & - & - & 23.7 & 21.9 & - & 24.3 \\
Maximal torque $(\mathrm{dNm})$ & - & - & 27.3 & 41.3 & - & 36.4 \\
$\Delta \mathrm{M}(\mathrm{dNm})$ & - & - & 3.6 & 19.4 & - & 12.1 \\
Scorch time $\left(t_{1}, \mathrm{~min}\right)$ & - & - & 3.0 & 1.2 & - & 1.2 \\
Optimum cure time $\left(t_{90}, \mathrm{~min}\right)$ & 5 & 5 & 4.9 & 5.3 & 5 & 3.5 \\
Cure rate index $\left(\mathrm{CRI}, \mathrm{min}^{-1}\right)$ & - & - & 52.9 & 24.0 & - & 42.2 \\
Thermal aging resistance $\left(R_{300}, \%\right)$ & - & - & 1.5 & 0.6 & - & 1.6 \\
\hline
\end{tabular}

It was observed that the increase of BIB caused a drop in minimal torque (ML) values (23.7 $\mathrm{dNm}$ to $21.9 \mathrm{dNm}$ for GTR/B BIB0.5 and GTR/B BIB2.0, respectively). During the modification process, the peroxide was added to the GTR. High shear forces acting on the mixing sample could result in the formulation of free radicals, which enhance reclaiming and modification of GTR. A higher reclaiming degree results in a higher amount of low molecular compounds and a more disintegrated polymeric network, which translates into lower resistance (better processing) during the early stage of curing characteristics. Due to this, the minimal torque value decreased.

The ML value for GTR/B DCP2.0 $_{2}(24.3 \mathrm{dNm})$ is $2.4 \mathrm{dNm}$ higher than $\mathrm{GTR} / \mathrm{B}_{\mathrm{BIB} 2.0}$. As mentioned previously, DCP has a lower capability to create free radicals than BIB, and as a result, the modification process was less efficient. $M_{H}$ values correspond with stiffness and shear modulus of cross-linked samples, while the torque increment $(\Delta \mathrm{M})$ is correlated with their cross-link density [27]. It was observed that with an increasing amount of BIB, the $M_{H}$ value increased (from 27.3 to $41.3 \mathrm{dNm}$, for GTR/B $B_{\text {BIB0.5 }}$ and GTR/B $B_{\text {BIB2.0, }}$, respectively) which was caused by the higher amount of used peroxide. The GTR/B $\mathrm{B}_{\mathrm{DCP} 2.0}$ was characterized with an $M_{H}$ value lower than GTR/B BIB2.0 ( 36.4 and $41.3 \mathrm{dNm}$, respectively) and $\Delta \mathrm{M}(12.1$ and $19.4 \mathrm{dNm}$, respectively), that only proves the lower efficiency of GTR modification and further reactive sintering in the presence of DCP than BIB.

The GTR/B $B_{\text {BIB } 0.5}$ and GTR/B $B_{\text {BIB2.0 }}$ were characterized by scorch time $\left(t_{1}\right)(3.0$ and $1.2 \mathrm{~min}$, respectively) and optimum curing time ( $\left.t_{90}\right)$ ( 4.9 and $5.3 \mathrm{~min}$, respectively), the same as GTR/B $\mathrm{B}_{\mathrm{DCP} 2.0}$ $\left(t_{1}-1.2 \mathrm{~min}\right.$ and $\left.t_{90}-3.5 \mathrm{~min}\right)$. Interestingly, regardless of the curing additive applied, the scorch time (when $2.0 \mathrm{phr}$ applied) was the same; however, due to the higher amount of active oxygen, the vulcanization process ends later $\left(t_{90}\right)$ for GTR/B BIB2.0. 
All samples were also analyzed in terms of cure rate index (CRI) and thermal aging resistance $\left(R_{300}\right)$. CRI shows how fast the studied sample was cured and the higher the value, the faster the process; however, this does not translate to the quality of the product and the efficiency of the process. In this case, CRI values for GTR/B BIB0.5 and GTR/B BIB2.0 were 52.9 and $24.0 \mathrm{~min}^{-1}$, respectively. The process is shorter for GTR/B $B_{B I B 0.5}$, only due to the small amount of curing agent, which resulted in the later start of the process $\left(t_{1}\right)$. In fact, the processes end at similar times $\left(t_{90}\right)$ so the CRI values should always be analyzed with a critical view. The CRI value for GTR/B $B_{\text {DCP2.0 }}$ was $42.2 \mathrm{~min}^{-1}$ which is significantly

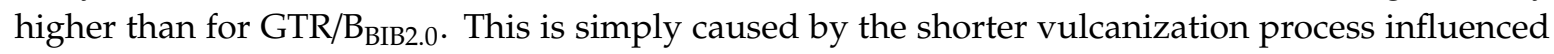
by the lower amount of created free radicals by DCP than BIB during the process. $R_{300}$ is the lowest for GTR/B $\mathrm{B}_{\mathrm{BIB} 2.0}(0.6 \%)$, while for GTR/B $\mathrm{B}_{\mathrm{BIB} 0.5}$ and GTR/B $\mathrm{B}_{\mathrm{DCP} 2.0}$, the values are similar $(1.5 \%$ and $1.6 \%$, respectively). It is well known [28] that polymers with a higher cross-linked structure offer a higher thermal stability as it is harder to reduce the molecular weight due to the higher amount of bonds to break. While $2.0 \mathrm{phr}$ BIB shows the best results in cross-linking than any of the studied samples $(\Delta \mathrm{M}$ and swelling degree — chapter 3.2), the $R_{300}$ parameter has the best value for GTR/B BIB2.0.

\subsection{Physico-Mechanical Properties}

The physico-mechanical properties of the studied samples are summarized in Table 4. At first, it can be noticed that the application of road bitumen decreased the tensile strength (from $3.2 \pm 0.1$ to $2.6 \pm 0.1 \mathrm{MPa}$ for GTR and GTR/B, respectively), increases elongation at break (from $176 \pm 6$ to $206 \pm 12 \%$ for GTR and GTR/B, respectively), decreased modulus at $100 \%$ of elongation (M100) (from 1.8 to $1.3 \mathrm{MPa}$ for GTR and GTR/B, respectively) as well as decreasing hardness (from $58 \pm 1$ to $49 \pm 1 \mathrm{Sh}$ A for GTR and GTR/B, respectively). Those changes are caused by the fact that the bitumen used acts as a plasticizer. In our previous studies [29], it was highlighted that in GTR, unreacted accelerators or other curing additives are present. During processing, those components can migrate within a sample, which facilitates the sintering process of GTR, resulting in a higher quality of the obtained revulcanizates. However, bitumen may capture migrating components as well as encapsulate GTR particles, decreasing cross-linking capability. Thus, as the amount of obtained cross-links is lower for GTR/B than GTR, the tensile strength, modulus at $100 \%$ and hardness decreases and at the same time, elongation at break increases.

Table 4. Physico-mechanical properties of modified GTR sintered at $180{ }^{\circ} \mathrm{C}$.

\begin{tabular}{|c|c|c|c|c|c|c|}
\hline \multirow{2}{*}{ Properties } & \multicolumn{6}{|c|}{ Sample Code } \\
\hline & GTR & GTR/B & GTR/B BIB0.5 & GTR/B BIB2.0 & GTR/B & $\mathrm{GTR} / \mathrm{B}_{\mathrm{DCP} 2.0}$ \\
\hline Tensile strength (MPa) & $3.2 \pm 0.1$ & $2.6 \pm 0.1$ & $3.1 \pm 0.1$ & $3.8 \pm 0.2$ & $3.0 \pm 0.2$ & $3.7 \pm 0.1$ \\
\hline Elongation at break (\%) & $176 \pm 6$ & $206 \pm 12$ & $170 \pm 7$ & $103 \pm 6$ & $206 \pm 12$ & $159 \pm 15$ \\
\hline M100 (MPa) & 1.8 & 1.3 & 1.5 & 3.6 & 1.4 & 2.4 \\
\hline Hardness (Sh A) & $58 \pm 1$ & $49 \pm 1$ & $55 \pm 1$ & $65 \pm 1$ & $57 \pm 1$ & $62 \pm 1$ \\
\hline Density at $25^{\circ} \mathrm{C}\left(\mathrm{g} / \mathrm{cm}^{3}\right)$ & $1.162 \pm 0.010$ & $1.142 \pm 0.011$ & $1.149 \pm 0.012$ & $1.18 \pm 0.011$ & $1.144 \pm 0.010$ & $1.149 \pm 0.013$ \\
\hline Swelling degree (\%) & $158 \pm 5$ & $175 \pm 4$ & $143 \pm 4$ & $107 \pm 4$ & $159 \pm 3$ & $130 \pm 2$ \\
\hline Sol fraction (\%) & $9 \pm 1$ & $17 \pm 2$ & $16 \pm 1$ & $14 \pm 1$ & $17 \pm 1$ & $15 \pm 1$ \\
\hline
\end{tabular}

The analysis of physico-mechanical properties of GTR modified with the addition of peroxides shows that the tensile strength of the obtained sample is similar regardless of the chemical modifier applied $\left(3.1 \pm 0.1,3.8 \pm 0.2,3.0 \pm 0.3\right.$ and $3.7 \pm 0.1 \mathrm{MPa}$ for GTR/B $\mathrm{B}_{\mathrm{BIB} 0.5}, \mathrm{GTR} / \mathrm{B}_{\mathrm{BIB} 2.0}, \mathrm{GTR} / \mathrm{B}_{\mathrm{DCP} 0.5}$, and $\mathrm{GTR} / \mathrm{B}_{\mathrm{DCP} 2.0}$, respectively). However, the type of peroxide has a significant influence on elongation at break values $\left(170 \pm 7,103 \pm 6,206 \pm 12\right.$ and $159 \pm 15 \%$ for GTR/B $B_{\text {BIB } 0.5}$, GTR/B $B_{\text {BIB2.0 }}$, GTR/B $/ B_{\text {DCP } 0.5}$, and GTR/B $\mathrm{B}_{\mathrm{DCP} 2.0}$, respectively). As curing characteristics indicated, samples cured with BIB were characterized by a more cross-linked structure, nevertheless, this phenomenon is not always desired. Creating too many cross-links might simply deteriorate the mechanical properties of a sample. An overly cross-linked structure is also confirmed by M100 values, as well as hardness. GTR/B $B_{\text {BIB2.0 }}$ shows a significantly higher M100 value than GTR/B $\mathrm{B}_{\mathrm{DCP} 2.0}$ (3.6 and 2.4 MPa, respectively) and hardness value 
( $65 \pm 1$ and $62 \pm 1$ ShA, respectively). For better visualization of the obtained results, strain-stress curves are presented in Figure 5. The density values do change significantly, only when the reference sample is compared to the rest of the test set $\left(1.162 \pm 0.01\right.$ to approx. $\left.1.142-1.149 \pm 0.01 \mathrm{~g} / \mathrm{cm}^{3}\right)$. This is caused by the presence of $10 \mathrm{phr}$ of the bitumen. It is worth mentioning that even though the curing curves were not recorded for GTR, GTR/B and GTR/B $\mathrm{B}_{\mathrm{DCP} 0.5}$ the properties of the samples are similar to those with

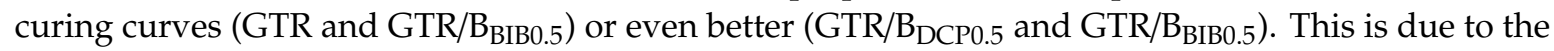
processing parameters. The sintering process of GTR is based on high temperature and high pressure. Those conditions are enough to initiate the reclaiming process, followed by revulcanization [30]. With that, it is possible to obtain a product with satisfactory parameters using no or a low amount of curing additives. However, the revulcanization process without any curatives may be at such a low level that it is not recorded by the rheometer.

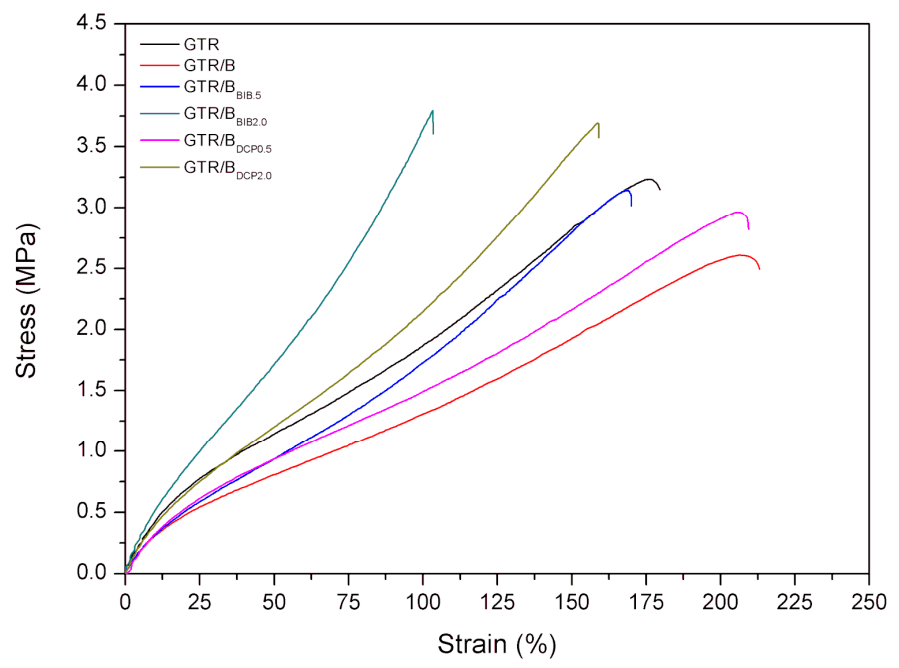

Figure 5. Stress-strain curves of modified GTR sintered at $180{ }^{\circ} \mathrm{C}$.

In order to better understand the changes occurring inside the studied samples during reclaiming and reactive sintering processes, four chosen physico-mechanical properties were compared with the swelling degree and presented in Figure 6. The degree of swelling allows the estimation of the structural changes of sintered GTR caused by curing reactions. The simple comparison of swelling degree with other properties allows an easier understanding of factors affecting the obtained results. Figure $6 \mathrm{~A}$ presents the relationship between swelling degree and tensile strength of the studied samples. The lower the swelling degree values, the higher the tensile strength values. Tensile strength is strictly connected with the amount of obtained cross-links during the curing process (more cross-links result in higher tensile strength) [31]. On the other hand, with more cross-links, it is more difficult to penetrate the structure of the sintered GTR with solvent, resulting in a lower swelling degree. In the case of elongation at break (Figure 6B), values rise with the increasing swelling degree. The strain of tested materials is connected with the type of matrix, the applied reinforcement and the possibility of polymer chains rotating and moving, which is partially dependent on the number of cross-links. Hardness, as well as tensile strength, are higher when the swelling degree decreases (Figure 6C), and it is also connected with the increase of the cross-linking degree. The sol fraction represents the loose macromolecules in the sample [32]. In the case of GTR, the sol fraction depends on the reclaiming degree, the number of unreacted additives and plasticizers. As can be noticed, the sol fraction of GTR $(9 \pm 1 \%)$ is visibly lower than the rest of the tested samples $(17 \pm 2,16 \pm 1,14 \pm 1,17 \pm 1$ and $15 \pm 1 \%$ for GTR/B, GTR/B BIB0.5, GTR/B BIB2.0, GTR/B $\mathrm{B}_{\mathrm{DCP} 0.5}$ and GTR/B $\mathrm{B}_{\mathrm{DCP} 2.0}$, respectively), which was caused by the presence of bitumen plasticizer extracted by the solvent during the measurement. In Figure $6 \mathrm{D}$, the dependence of the swelling degree on the sol fraction is presented. Excluding the reference sample, the sol fraction is similar for every sample and the influence of peroxides on reclaiming degree and consequently, further sintering of GTR is interrupted by the presence of bitumen. 

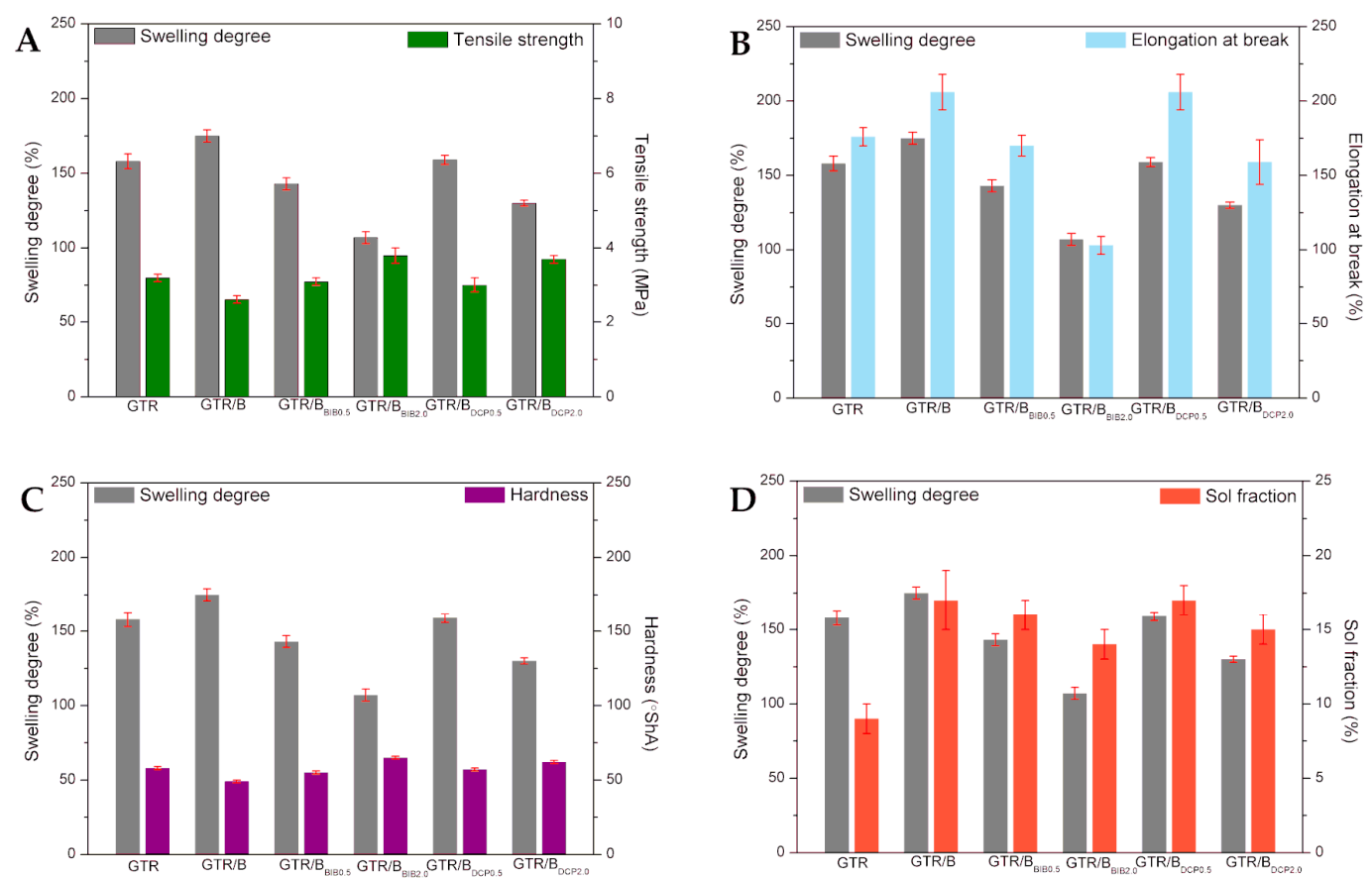

Figure 6. Comparison of swelling degree with: (A) tensile strength, (B) elongation at break, (C) hardness and (D) sol fraction of studied samples.

During the studies, in the case of GTR treated with $2.0 \mathrm{BIB}$, it can be noticed that $24 \mathrm{~h}$ after the revulcanization process, the blooming occurred, leaving yellowish powder on the surface. The FTIR analysis showed that the bloomed compound is BIB or BIB derivative (FTIR analysis not included in the article). The quality of the surfaces in terms of the type and amount of peroxides is presented in Figure 7. It must be highlighted that the application of any modifier, which results in blooming, must be studied further in order to find a proper replacement for the component or to establish new composition, preventing from blooming. The presence of easily removable powder on the surface comes with environmental risk (uncontrolled release to the environment) and may influence the health of workers dealing with that kind of material.
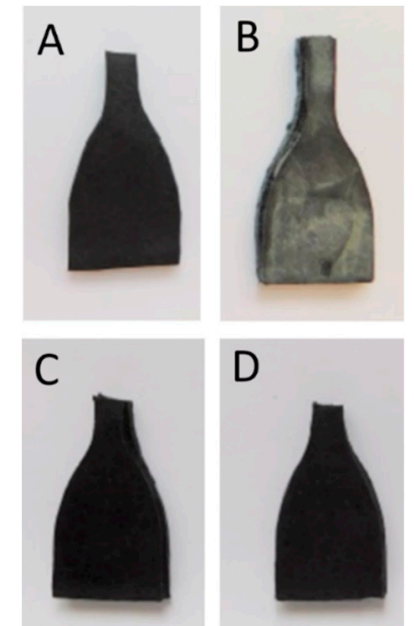

Figure 7. Appearance of the sample $24 \mathrm{~h}$ after reactive sintering: (A) GTR/B $B_{B I B 0.5}$, (B) GTR/B $B_{B I B 2.0}$, (C) GTR/B $\mathrm{B}_{\mathrm{DCP} 0.5}$, (D) GTR/B $\mathrm{B}_{\mathrm{DCP} 2.0}$. 


\section{Conclusions}

In this study, GTR was reclaimed at low temperatures by applying mechano-chemical treatment via milling in the presence of road bitumen 100/150 and two types of peroxides: (i) di-(2-tert-butyl-peroxyisopropyl)-benzene and (ii) dicumyl peroxide. The influence of the amount and type of peroxides on the curing characteristics and physico-mechanical properties was evaluated. The results indicate that the application of bitumen as a plasticizer significantly improves the processing of GTR, which is one of the critical parameters for GTR recycling. Decreasing the amount of energy put into the process (lower forces on the motor due to the presence of bitumen) may result in a significant decrease in the processing cost. The type and amount of added peroxides have a notable influence on curing characteristics, as well as physico-mechanical properties; however, it is possible to obtain a product with satisfactory properties even though the curing curve was not recorded (GTR and $\left.\mathrm{GTR} / \mathrm{B}_{\mathrm{DCP} 0.5}\right)$. It was found out that the structure of peroxides plays an important role in cross-link creation, which is reflected in the physico-mechanical properties. As BIB poses a higher amount of active oxygen, creating more cross-links, the GTR modified with the peroxide was characterized by a similar tensile strength, lower elongation at break, higher modulus at $100 \%$, a similar hardness, a lower swelling degree and slightly lower sol fraction compared to samples cured with DCP. Moreover, it was noticed that in sample GTR/B BIB2.0, surface blooming occurred. The aforementioned characteristics of the obtained revulcanized GTR samples indicate that dicumyl peroxide is a better curative in terms of physico-mechanical properties as well as health and environmental issues (blooming).

Author Contributions: Conceptualization, K.F.; experimental part: Ł.Z., M.P.-R. and K.F.; measurements: Ł.Z., M.P.-R. and K.F.; data analysis: Ł.Z., J.H., and K.F.; data interpretation: Ł.Z., J.H., S.W., and K.F.; writing-original draft preparation: Ł.Z. and K.F.; writing-review, and editing: Ł.Z., J.H., S.W., and K.F. All authors have read and agreed to the published version of the manuscript.

Funding: This research was funded by National Center for Research and Development (Poland) grant number [LIDER/6/0035/L-8/16/NCBR/2017].

Conflicts of Interest: The authors declare no conflict of interest.

\section{References}

1. Mitchell, N.C. Process of Reclaiming Rubber from Waste-Rubber Goods. U.S. Patent US419697, 21 January 1890.

2. Garlick, F.W.; Bear, C.I.; Vail, W.A.; Wheeler, O.A. Art or Process of Reclaiming Scrap or Waste Vulcanized Rubber. U.S. Patent US866759, 24 September 1907.

3. Lovette, N.G. Process for Reclaiming Rubber, Metal and Fabric from Whole Tires. U.S. Patent US4025990, 28 April 1976.

4. Kim, J.K.; Lee, S.H. New technology of crumb rubber compounding for recycling of waste tires. J. Appl. Polym. Sci. 2000, 78, 1573-1577. [CrossRef]

5. De, D.; Das, A.; De, D.; Dey, B.; Debnath, S.C.; Roy, B.C. Reclaiming of ground rubber tire (GRT) by a novel reclaiming agent. Eur. Polym. J. 2006, 42, 917-927. [CrossRef]

6. Asaro, L.; Gratton, M.; Seghar, S.; Aït Hocine, N. Recycling of rubber wastes by devulcanization. Resour. Conserv. Recycl. 2018, 133, 250-262. [CrossRef]

7. Formela, K.; Hejna, A.; Zedler, Ł.; Colom, X.; Cañavate, J. Microwave treatment in waste rubber recycling-Recent advances and limitations. Express Polym. Lett. 2019, 13, 565-588. [CrossRef]

8. Adhikari, B.; De, D.; Maiti, S. Reclamation and recycling of waste rubber. Prog. Polym. Sci. 2000, 25, 909-948. [CrossRef]

9. Nadal, M.; Rovira, J.; Díaz-Ferrero, J.; Schuhmacher, M.; Domingo, J.L. Human exposure to environmental pollutants after a tire landfill fire in Spain: Health risks. Environ. Int. 2016, 97, 37-44. [CrossRef] 
10. Jang, J.-W.; Yoo, T.-S.; Oh, J.-H.; Iwasaki, I. Discarded tire recycling practices in the United States, Japan and Korea. Resour. Conserv. Recycl. 1998, 22, 1-14. [CrossRef]

11. Ogilvie, G.; Macdonald, K.; Karlik-Neale, M. Product Stewardship Case Study for End-of-Life Tyres; Raport of URS: Wellington, New Zealand, 2006.

12. Torretta, V.; Rada, E.C.; Ragazzi, M.; Trulli, E.; Istrate, I.A.; Cioca, L.I. Treatment and disposal of tyres: Two EU approaches. A review. Waste Manag. 2015, 45, 152-160. [CrossRef]

13. Karger-Kocsis, J.; Mészáros, L.; Bárány, T. Ground tyre rubber (GTR) in thermoplastics, thermosets, and rubbers. J. Mater. Sci. 2013, 48, 1-38. [CrossRef]

14. Ramarad, S.; Khalid, M.; Ratnam, C.T.; Chuah, A.L.; Rashmi, W. Waste tire rubber in polymer blends: A review on the evolution, properties and future. Prog. Mater. Sci. 2015, 72, 100-140. [CrossRef]

15. Arastoopour, H.; Schocke, D.A.; Bernstein, B.; Bilgili, E. Process for Recycling of Rubber Materials. U.S. Patent US5904885, 18 May 1999.

16. Saiwari, S.; Dierkes, W.K.; Noordermeer, J.W.M. Comparative investigation of the devulcanization parameters of tire rubbers. Rubber Chem. Technol. 2014, 87, 31-42. [CrossRef]

17. Sabzekar, M.; Chenar, M.P.; Mortazavi, S.M.; Kariminejad, M.; Asadi, S.; Zohuri, G. Influence of process variables on chemical devulcanization of sulfur-cured natural rubber. Polym. Degrad. Stab. 2015, 118, 88-95. [CrossRef]

18. De, D.; De, D.; Singharoy, G.M. Reclaiming of ground rubber tire by a novel reclaiming agent. I. Virgin natural rubber/reclaimed GRT vulcanizates. Polym. Eng. Sci. 2007, 47, 1091-1100. [CrossRef]

19. Thaicharoen, P.; Thamyongkit, P.; Poompradub, S. Thiosalicylic acid as a devulcanizing agent for mechano-chemical devulcanization. Korean J. Chem. Eng. 2010, 27, 1177-1183. [CrossRef]

20. Ostad, M.S.; Ansarifar, A.; Karbalaee, S.; Athary Far, S. Devulcanization and recycling of waste automotive EPDM rubber powder by using shearing action and chemical additive. Prog. Rubber Plast. Recycl. Technol. 2015, 31, 87-116.

21. Neto, J.R.A.; Visconte, L.L.Y.; Tavares, M.I.B.; Pacheco, E.B.A.V.; Furtado, C.R.G. Regeneration of vulcanized compounds based on butadiene-styrene copolymer. Int. J. Polym. Mater. Polym. Biomater. 2007, 56, 565-578. [CrossRef]

22. Formela, K.; Cysewska, M.; Januszewicz, K. Effect of addition of reclaimed rubber on curing characteristics and mechanical properties of styrene-butadiene rubber. Przem. Chem. 2014, 93, 666-671.

23. Sabzekar, M.; Zohuri, G.; Chenar, M.P.; Mortazavi, S.M.; Kariminejad, M.; Asadi, S. A new approach for reclaiming of waste automotive EPDM rubber using waste oil. Polym. Degrad. Stab. 2016, 129, 56-62. [CrossRef]

24. Formela, K.; Klein, M.; Colom, X.; Saeb, M.R. Investigating the combined impact of plasticizer and shear force on the efficiency of low temperature reclaiming of ground tire rubber (GTR). Polym. Degrad. Stab. 2016, 125, 1-11. [CrossRef]

25. Khang, T.H.; Ariff, Z.M. Vulcanization kinetics study of natural rubber compounds having different formulation variables. J. Therm. Anal. Calorim. 2012, 109, 1545-1553. [CrossRef]

26. Yazdani, H.; Karrabi, M.; Ghasmi, I.; Azizi, H.; Bakhshandeh, G.R. Devulcanization of waste tires using a twin-screw extruder: The effects of processing conditions. J. Vinyl Addit. Technol. 2011, 17, 64-69. [CrossRef]

27. Kim, S.W.; Park, H.Y.; Lim, J.C.; Jeon, I.R.; Seo, K.H. Cure characteristics and physical properties of ground-rubber-filled natural rubber vulcanizates: Effects of the curing systems of the ground rubber and rubber matrix. J. Appl. Polym. Sci. 2007, 105, 2396-2406. [CrossRef]

28. Ray, S.; Cooney, R.P. Chapter 7: Thermal degradation of polymer and polymer composites. In Handbook of Environmental Degradation of Materials; Kutz, M., Ed.; William Andrew Publishing (Elsevier): Norwich, NY, USA, 2013.

29. Zedler, Ł.; Colom, X.; Saeb, M.R.; Formela, K. Preparation and characterization of natural rubber composites highly filled with brewers' spent grain/ground tire rubber hybrid reinforcement. Compos. Part B Eng. 2018, 145, 182-188. [CrossRef]

30. Morin, J.E.; Williams, D.E.; Farris, R.J. A novel method to recycle scrap tires: High-pressure high-temperature sintering. Rubber Chem. Technol. 2002, 75, 955-968. [CrossRef] 
31. Zhao, F.; Bi, W.; Zhao, S. Influence of crosslink density on mechanical properties of natural rubber vulcanizates. J. Macromol. Sci. Part B Phys. 2011, 50, 1460-1469. [CrossRef]

32. Nandi, S.; Winter, H.H. Swelling behavior of partially cross-linked polymers: A ternary system. Macromolecules 2005, 38, 4447-4455. [CrossRef]

(C) 2019 by the authors. Licensee MDPI, Basel, Switzerland. This article is an open access article distributed under the terms and conditions of the Creative Commons Attribution (CC BY) license (http://creativecommons.org/licenses/by/4.0/). 